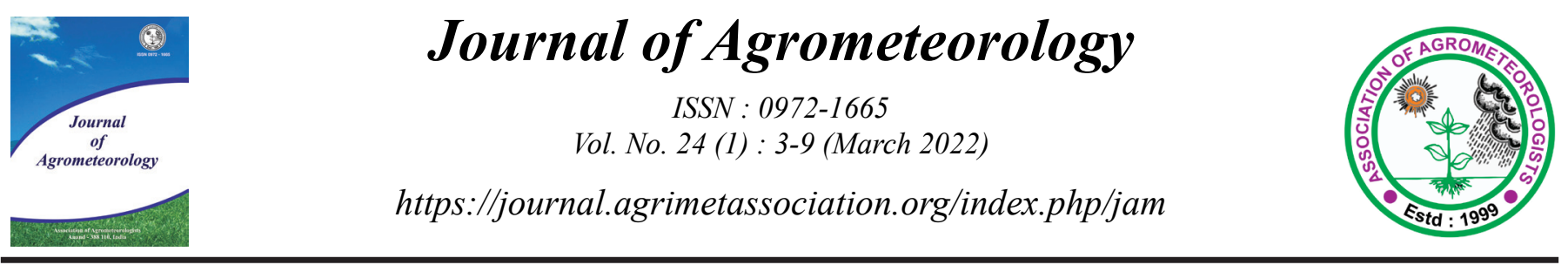

Research Paper

\title{
Evaluating radiation interception pattern and RUE of green gram grown in Lower Gangetic Plains and assessing future yield based on RUE
}

\author{
SARATHI SAHA ${ }^{1}$, SAON BANERJEE ${ }^{1 *}$, SOUMEN MONDAL ${ }^{2}$, ASIS MUKHERJEE ${ }^{1}$, RAJIB NATH ${ }^{3}$ \\ and SHIBANI CHOWDHURY ${ }^{4}$
}

${ }^{1}$ Dept of Agril Meteorology \& Physics, BCKV, Mohanpur, Nadia, India

${ }^{2}$ Dept of Agronomy, UBKV. Pundibari, Coochbehar, India

${ }^{3}$ Dept of Agronomy, BCKV, Mohanpur, Nadia, India

${ }^{4} R R S$, BCKV, Kakdwip, South 24 Parganas, India

*Correspondening author email ․sbaner2000@yahoo.com

\begin{abstract}
An experiment was conducted in the Lower Gangetic Plains of West Bengal during 2017 and 2018 with three popular green gram varieties of the region (viz. Samrat, PM05 and Meha). Along with studying the variation of PAR components, a radiation use efficiency (RUE) based equation irrespective of varieties was developed and used to estimate the green gram yield for 2040-2090 period under RCP 4.5 and 8.5 scenarios. Field experimental results showed that almost 33.33 to $52.12 \%$ higher yield was recorded in 2017 in comparison to 2018 . As observed through pooled experimental data of two years, $P M 05$ produced 3 to $4 \%$ higher pod and 4 to $15 \%$ more biomass than Samrat and Meha with the highest radiation use efficiency $\left(1.786 \mathrm{~g} \mathrm{MJ}^{-1}\right)$. Results also depicted that enhanced thermal condition would cause 9 to 15 days of advancement in maturity. Biomass and yield would also decrease gradually from 2040 to 2090 with an average rate of $7.60-11.70 \%$ and $10.19-14.17 \%$ respectively. The supporting literature confirms that future yield prediction under projected climate based on "radiation to biomass" conversion efficiency can be used successfully as a method to evaluate climate change impact in agriculture.
\end{abstract}

Key words: Absorbed PAR, Green gram, Intercepted PAR, Radiation use efficiency

Growth, development and production of crops are the outcomes of photosynthesis process. Capacity of harnessing and utilizing resources to generate dry matter largely relies upon the development of photosynthesizing area and pattern of intercepted radiation. That means, photosynthetic activity regulating the biomass production and yield of crop is directly related to PAR interception and PAR absorption and the efficiency of interception during the crop growing season (Brar et al., 2006). The absorptive nature of crops differs with a number of factors like leaf angle, structure, age and other morphological features. The conversion efficiency of intercepted PAR into dry matter is another important yield determining factor. This conversion factor is commonly denoted by the term 'radiation use efficiency' (RUE).

Green gram, being a short duration, drought tolerant, hardy legume crop, is receiving huge acceptance by the Indian farmers. The crop is gaining priority in the present context of climate change. This pulse is extensively cultivated in the fertile
New Alluvial Zone of West Bengal. A lot of studies have been conducted to evaluate the future yield and overall performance of several crops (Kumar et al., 2012; Yadav et al., 2012a). Most of them employed complex approaches require vast dataset and computer based programming. Thus, research on yield assessment for green gram in Lower-Gangetic plains of West Bengal is rarely available. Hence, a field experiment was conducted during 2017 and 2018 to observe the variation of PAR components and PAR interception pattern throughout the crop growing period and their influence on the final produce. The main objective of the research paper is to develop the radiation use efficiency (RUE) based yield prediction equation. Another objective of the present study was to predict the yield impacted by future climatic condition using the RUE based equation.

\section{MATERIAL AND METHODS}

The field experiment was performed in the research farm 
of Bidhan Chandra Krishi Viswavidyalaya, Kalyani, Nadia, West Bengal, India (Lat $22^{\circ} 58^{\prime} \mathrm{N}$ and Long $88^{\circ} 31^{\prime} \mathrm{E}$ ). The experimental field comes under New Alluvial Zone of West Bengal and it has the physiographic and climatic qualities which represent the lower Indo-Gangetic Plain.

Three local varieties of green gram, namely Samrat, PM05 and Meha were selected for the two years' study. Seeds were sown on $17 / 09 / 2017$ and $24 / 09 / 2018$, just after the harvesting of jute with a spacing of $30 \mathrm{~cm} \times 10 \mathrm{~cm}$. This sowing window used in the present experiment does not typically belong to Kharif or Rabi season. It helps to avoid the cool weather of December end and January during pod formation and crop maturity. In general, 26.6 to $32.7^{\circ} \mathrm{C}$ maximum temperature and 12.5 to $25.5^{\circ} \mathrm{C}$ minimum temperature and 2.9 to $295.3 \mathrm{~mm}$ rainfall prevail during the growing period in the study area. Three replications were maintained to obtain more accurate results. Conventional set of management practices and intercultural operations were followed.

Stage wise dry matter accumulation was determined from the weight of oven dried plant samples. The final yield was calculated from the harvested pods. Yield and plant biomass were expressed in $\mathrm{t} \mathrm{ha}^{-1}$. Samplings and observations were taken from specific phenological stages, namely Vegetative, End of flowering, $1^{\text {st }}$ pod formation, End of pod formation, $50 \%$ maturity and $100 \%$ maturity.

Data of weather parameters (maximum and minimum temperature, rainfall) prevailing during the crop growing season were collected from the Meteorological Observatory, Kalyani which is situated at the close proximity with the experimental plot.

A Line Quantum Sensor (Model: APOGEE/MQ-301) was placed $50 \mathrm{~cm}$ above crop height and $5 \mathrm{~cm}$ above soil surface respectively to measure the incident PAR and transmitted PAR. Reflected PAR from crop and soil were recorded by inverting the sensor and placing it above crop surface and soil surface respectively. Values of different components of PAR, averaged over whole day, were collected for each growth stage. The values of the PAR components were measured in $\mu \mathrm{mol} \mathrm{m} \mathrm{m}^{-2} \mathrm{~s}^{-1}$ unit and later they were converted to $\mathrm{Wm}^{-2}$ with the conversion factor 4.6. As 4.6 micro-mole ( $\mu$ mole) is equivalent to 1 joule, and 1 joule per second equals to 1 watt, thus through this conversion factor, $\mu \mathrm{mol} \mathrm{m} \mathrm{m}^{-2} \mathrm{~s}^{-1}$ is converted to $\mathrm{W} \mathrm{m}^{-2}$. The relationship is as follows:

$\mathrm{X} \mu \mathrm{mol} \mathrm{m} \mathrm{m}^{-2} \mathrm{~s}^{-1}=\mathrm{X} / 4.6 \mathrm{~J} \mathrm{~m}^{-2} \mathrm{~s}^{-1}=\mathrm{X} / 4.6 \mathrm{~W} \mathrm{~m}^{-2}$ (Here, $\mathrm{X}$ is any arbitrary number)

Intercepted photosynthetically active radiation (IPAR) was computed as:

Intercepted PAR $($ IPAR $)=($ Incident PAR - Transmitted PAR) (Nobel, 1980) (1)

Absorbed photosynthetically active radiation (APAR) was calculated as follows:

Absorbed PAR $($ APAR $)=\{($ Incident PAR + PAR reflected from soil) - (Transmitted PAR + PAR reflected from crop) $\}$ (Gallo and Daughtry, 1986)..

\section{Estimation of radiation use efficiency (RUE)}

In the present study, it was considered that radiation use efficiency and PAR use efficiency were same, as the calculations were based on IPAR. RUE is defined as the biomass produced per unit of intercepted photosynthetically active radiation. It is the slope of the curve generated from accumulated IPAR and accumulated biomass value (Kiniry et al., 2001). In case of determination of RUE, above ground biomass (AGB) comprising of leaf, stem and pod biomasses $\left(\mathrm{g} \mathrm{m}^{-2}\right.$ day $\left.^{-1}\right)$ were plotted against accumulated intercepted PAR, through multiplication of IPAR value (in $\mathrm{W} \mathrm{m}^{-2}$ unit) with time. As the standard expression of RUE is $\mathrm{g} \mathrm{MJ}^{-1}$, unit of Intercepted PAR was converted to $\mathrm{MJ} \mathrm{m}^{-2} \mathrm{day}^{-1}$ from $\mathrm{Wm}^{-2}$ for expediency of the calculation. The variation of IPAR, APAR and RUE are explained with the two years' pooled yield, biomass and PAR data for convenience of the study.

\section{Assessing the future yield based on RUE}

The time span between 2040 and 2090 was considered as the study period for future yield estimation. A RUE based yield predicting equation irrespective of varieties was developed for the study region. Temperature and GSR (global solar radiation) data for 2040 to 2090 were generated from Marksim weather generator under two RCP scenarios (4.5 and 8.5). RCP 4.5 is an intermediate scenario which assumes the emissions to decline after 2040. But RCP 8.5 is an extreme scenario of climate change condition considering continuous to rise of emissions throughout the $21^{\text {st }}$ century. So, both moderate to extreme consequences can be checked by using these two RCPs. GSR was converted to incident PAR assuming the incident PAR to be $48 \%$ of GSR. Beer Lambert's law which shows the attenuation of solar beam through plant canopy was employed to calculate the intercepted PAR (IPAR) for each phenophase. The observed values of stage-wise LAI, found from the two years study and extinction coefficient value of 0.56 as per Koocheki et al. (2016) were considered for IPAR estimation. Then IPAR values were accumulated over the crop duration. Prior to that, the 'future crop duration' was estimated with the help of GDD (growing degree days) values. Biomass for the study period was worked out from the RUE based equation and multiplying it by the conversion factor provides the future yield of green gram. The conversion factor in this case was set to the value of 0.5 which was obtained from the biomass to yield conversion relation of this biennial experiment. Average values of two years' accumulated biomass and yield were considered as the current yield parameters of green gram. Deviation of future yield from the current production level has been expressed in percentages $(\%)$.

Thus, the equations used in this section are:

Incident $\mathrm{PAR}=\mathrm{GSR} * 0.48$

Intercepted PAR $($ IPAR $)=$ Incident PAR $\mathrm{e}^{-\left(\mathrm{k}^{*} \mathrm{LAI}\right)}[\mathrm{k}=$ extinction coeff. (0.56)] ....

Yield $=$ Biomass $*$ conversion factor $(0.5)$

Statistical analysis of the obtained yield and biomass data was done by the IBM SPSS software. The significance of yield and biomass difference was tested at 5\% significance level. 
Table 1: Yield and plant biomass at maturity achieved by Samrat, PM05 and Meha varieties

\begin{tabular}{lcccc}
\hline \multirow{2}{*}{ Varieties } & \multicolumn{2}{c}{$1^{\text {st }}$ Year $(2017)$} & \multicolumn{2}{c}{$2^{\text {nd }}$ Year $(2018)$} \\
\cline { 2 - 5 } & $\begin{array}{c}\text { Yield } \\
\left(\mathrm{t} \mathrm{ha}^{-1}\right)\end{array}$ & Plant Biomass at maturity $\left(\mathrm{t} \mathrm{ha}^{-1}\right)$ & $\begin{array}{c}\text { Yield } \\
\left(\mathrm{t} \mathrm{ha}^{-1}\right)\end{array}$ & $\begin{array}{c}\text { Plant Biomass at maturity } \\
(\mathrm{t} \text { ha }\end{array}$ \\
\hline Samrat $\left(\mathrm{V}_{1}\right)$ & 1.65 & 2.68 & 0.79 & 1.74 \\
PM05 $\left(\mathrm{V}_{2}\right)$ & 1.53 & 3.00 & 1.02 & 2.19 \\
Meha $\left(\mathrm{V}_{3}\right)$ & 1.62 & 2.88 & 0.86 & 2.11 \\
\hline
\end{tabular}

Table 2: Days to attain the phonological stages by the varieties in experimental years $\left(\mathrm{Y}_{1}: 2017\right.$ and $\left.\mathrm{Y}_{2}: 2018\right)$

\begin{tabular}{lcccccc}
\hline \multirow{2}{*}{ Phenological stages } & \multicolumn{2}{c}{ Samrat } & \multicolumn{2}{c}{ PM05 } & \multicolumn{2}{c}{ Meha } \\
\cline { 2 - 7 } & $\mathrm{Y}_{1}$ & $\mathrm{Y}_{2}$ & $\mathrm{Y}_{1}$ & $\mathrm{Y}_{2}$ & $\mathrm{Y}_{1}$ & $\mathrm{Y}_{2}$ \\
\hline Vegetative & 16 & 15 & 18 & 16 & 17 & 16 \\
End of flowering & 30 & 30 & 31 & 31 & 31 & 32 \\
$1^{\text {st }}$ pod formation & 39 & 37 & 40 & 36 & 40 & 38 \\
End of pod formation & 45 & 49 & 46 & 48 & 46 & 50 \\
$50 \%$ maturity & 61 & 59 & 63 & 59 & 63 & 60 \\
$100 \%$ maturity & 76 & 68 & 78 & 69 & 78 & 69 \\
\hline
\end{tabular}

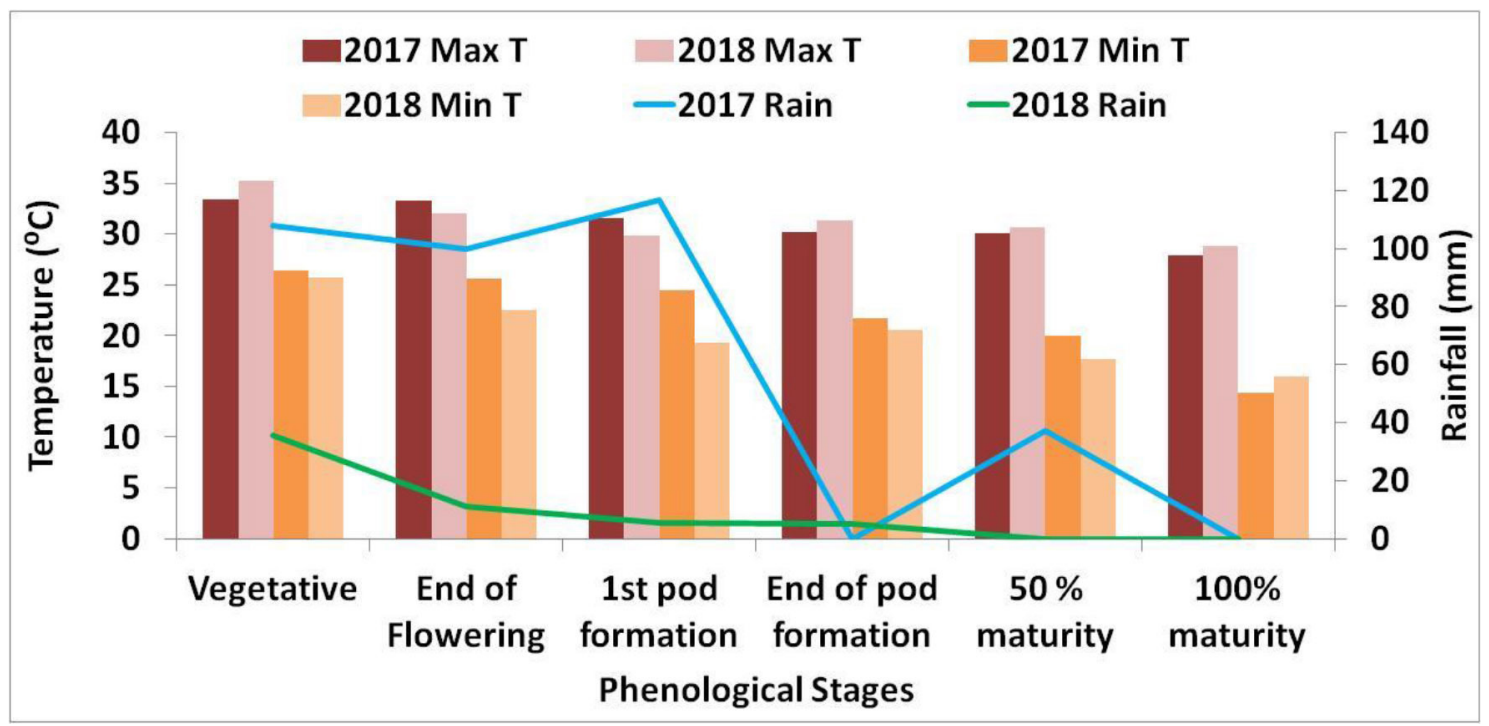

Fig.1: Variation of temperature (maximum and minimum temperature) and rainfall in different phenophases of green gram varieties during the experiment

\section{RESULTS AND DISCUSSION}

The overall performances of all the three varieties with respect to the prevailing weather condition in the said experimental years was observed first, followed by PAR interception and absorption pattern. Thereafter, the RUE was estimated and based on RUE future performance of green gram was evaluated.

General effect of weather parameters on yield and biomass produced by the varieties

It was observed that all the three varieties produced higher yield and biomass in 2017 (Table 1). Yield and plant biomass were almost 33.33 to $52.12 \%$ and 26.74 to $35.07 \%$ greater in the first year of experiment respectively compared to second year. The crop also took more time to attain 100\% maturity in 2017 (Table 2). Comparatively higher amount of maximum temperature (Max T) in most of the phenophases and minimum temperature (Min T) during maturity were prevailed during 2018 crop growing season. During maturity stage of second year cropping season, around 3\% higher maximum and more than $10 \%$ higher minimum temperature was prevailed compared to the previous year. This greater temperature range might have affected the yield of 2018 sown crop through shortening the maturity process. A total rainfall of $421.17 \mathrm{~mm}$ throughout the growing period was recorded from 2017, where as the crop growing season of the next year received only $56.8 \mathrm{~mm}$ rainfall. Lower maximum temperature along with the higher amount of rainfall during initial crop growth phase of 2017 also helped to achieve better yield attribute in that year (Fig.1).

The study on varietal response revealed that PM05 accumulated the highest biomass followed by Meha and Samrat in both years. The highest yield was reported from Samrat and PM05 in 2017 and 2018 respectively. But PM05 achieved the highest 
Table 3: Statistical analysis of yield as dependent variables

\begin{tabular}{|c|c|c|c|c|c|}
\hline \multicolumn{6}{|c|}{ Dependent Variable: yield } \\
\hline Source & Type III Sum of Squares & df & Mean Square & $\mathrm{F}$ & Sig. \\
\hline Corrected Model & $2.727^{\mathrm{a}}$ & 9 & 0.303 & 3.973 & 0.032 \\
\hline Intercept & 28.000 & 1 & 28.000 & 367.148 & 0.000 \\
\hline rep(year) & 0.371 & 4 & 0.093 & 1.218 & 0.375 \\
\hline treatment & 0.008 & 2 & 0.004 & 0.056 & 0.946 \\
\hline Total & 31.338 & 18 & & & \\
\hline Corrected Total & 3.337 & 17 & & & \\
\hline \multicolumn{6}{|c|}{ a. $\mathrm{R}$ Squared $=0.817($ Adjusted R Squared $=0.612)$} \\
\hline
\end{tabular}

Table 4: Variation of accumulated Intercepted PAR of the three varieties throughout the growing period

\begin{tabular}{lccc}
\hline \multicolumn{1}{c}{ Growth Stages } & \multicolumn{3}{c}{ IPAR $\left(\mathrm{Wm}^{2-}\right)$} \\
\cline { 2 - 4 } & Samrat & PM05 & Meha \\
\hline Vegetative & 77.66 & 72.2 & 80.9 \\
End of flowering & 196.46 & 202.88 & 211.06 \\
1st pod formation & 356.79 & 339.56 & 355.65 \\
End of pod formation & 506.27 & 495.29 & 512.5 \\
50\% maturity & 630.1 & 636.65 & 655.6 \\
100\% maturity & 726.02 & 741.76 & 752.09 \\
\hline
\end{tabular}

average yield and biomass. It yielded $4.31 \%$ and $2.75 \%$ higher pod than Samrat and Meha respectively. Plant biomass of PM05 was also $14.84 \%$ and $3.85 \%$ more than the other two varieties. On the other hand, Samrat was recorded with an average of $1.22 \mathrm{t} \mathrm{ha}^{-1}$ yield and $2.21 \mathrm{t} \mathrm{ha}^{-1}$ plant biomass, both of which was the lowest compared to other two. But no significant difference was found for either yield or plant biomass among the varieties (Table 3).

\section{Interception of PAR: varietal response}

The IPAR, accumulated by different varieties during experiment in all the growth stages, are displayed in the Table 4.

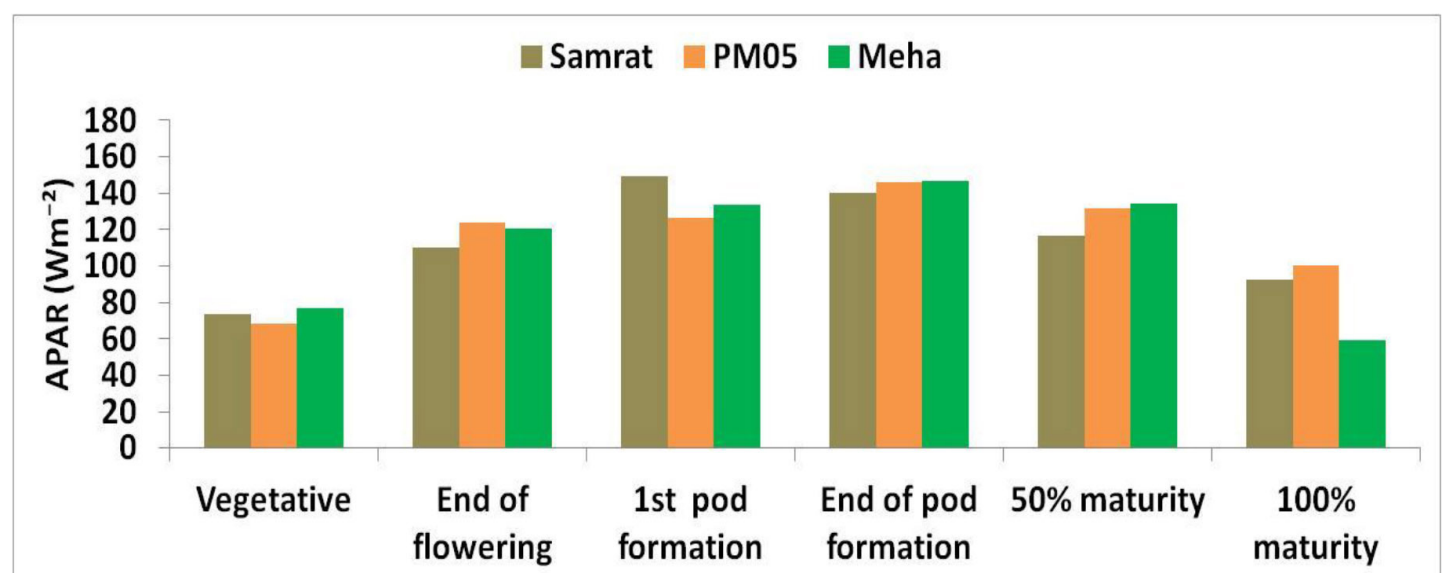

Fig.2: Absorption of PAR by Samrat, PM05 and Meha throughout the phenphases

Similarity was found in the pattern of interception for all of them. But values and variation percentages of IPAR differed from variety to variety. Difference in leaf architecture was one of the prime reasons. The lowest amount of PAR was intercepted in the vegetative stage when the canopy was partially developed and eventually increased with the advancement of the growth stages and touched the peak value in the $1^{\text {st }}$ pod formation stage. IPAR value again reduced at $100 \%$ maturity stage due to senescence of the leaves.

Comparison of the three varieties revealed that the plants of Meha variety accumulated the highest amount of cumulative IPAR. The interception of PAR by Meha was 3.59\% and $1.39 \%$ greater than Samrat and PM05 respectively. Cumulative IPAR value for Samrat was the lowest. Average yield and plant biomass recorded from
Samrat was minimum as well. So, in this case PAR interception was directly related with final yield and biomass. But Meha gave less yield and biomass than PM05 in spite of intercepting highest PAR. Dark coloured leaves of PMO5 may be one of the reasons behind it. However, this result can be well explained by the observations on absorbed PAR.

\section{Absorption of PAR: varietal response}

The variation of average absorbed PAR throughout all the growth stages for Samrat, PM05 and Meha varieties are shown in Fig. 2. The pattern of PAR absorption followed the trend of intercepted PAR for all the varieties. $73.88 \mathrm{Wm}^{-2}$ to $148.97 \mathrm{Wm}^{-2}, 68.18 \mathrm{Wm}^{-2}$ to $146.11 \mathrm{Wm}^{-2}$ and $76.93 \mathrm{Wm}^{-2}$ to $146.74 \mathrm{Wm}^{-2}$ were the ranges of 
Table 5: Performance of green gram in future under RCP 4.5 and RCP 8.5 scenarios

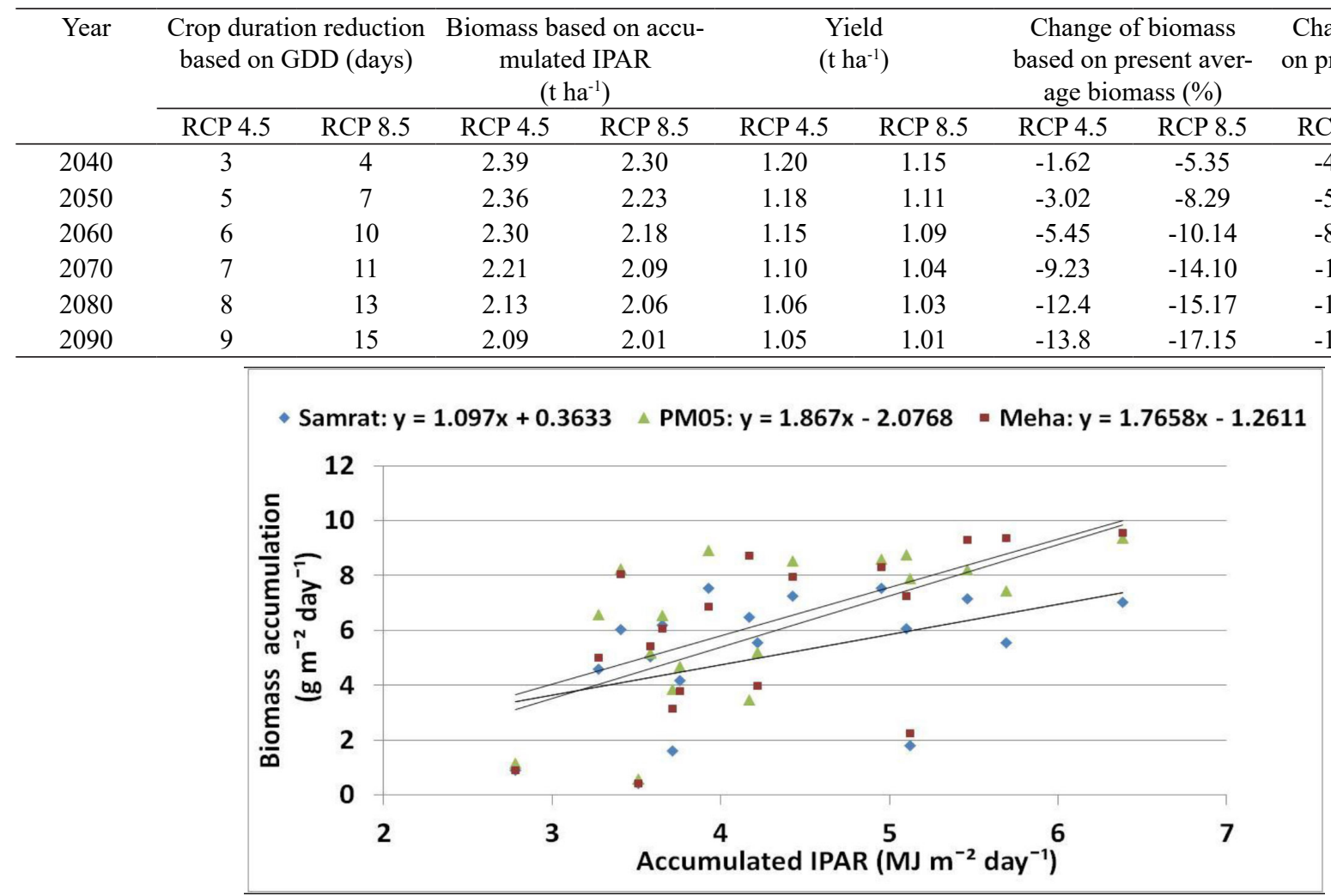

Fig.3: Relationship between accumulated biomass and accumulated IPAR for Samrat, PM05 and Meha variety

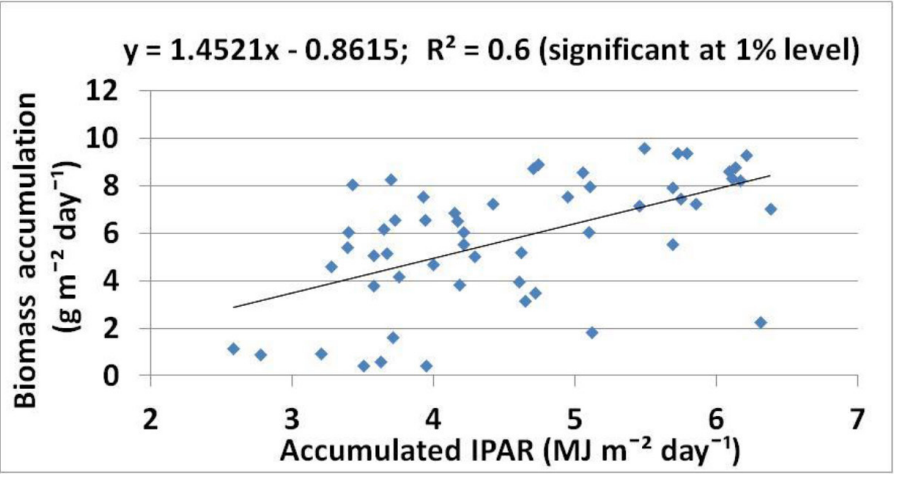

Fig.4: Relationship between accumulated biomass and accumulated IPAR of green gram (combining all three varieties under study to develop the RUE irrespective of varieties)

PAR absorbed by Samrat, PM05 and Meha, respectively. Initially absorption of PAR was minimum for PM05; but for subsequent stages the values of APAR increased considerably. Among the three varieties, Meha was recorded with the lowest fraction of PAR absorption. The typical plant shape of Samrat variety hindered it from capturing greater amount of PA R. On the other hand, Meha and PM05 had compact structure, leading to better interception. The darker leaves with alternate arrangement aided in greater absorption of PAR in PM05.

\section{Radiation use efficiency (RUE)}

RUE values were worked out separately for the three varieties. RUE of Samrat, PM05 and Meha were found in the tune

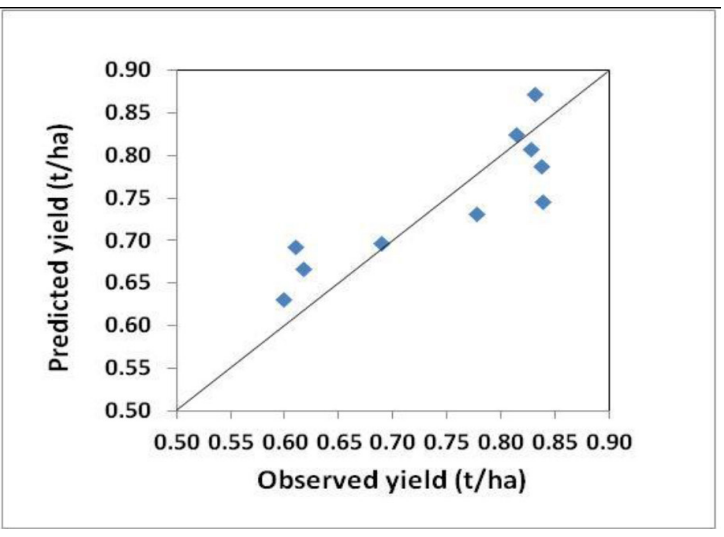

Fig. 5: Comparison between the actual and predicted yield of green gram for the period of 2007-2016 through 1:1 line

of $1.097 \mathrm{~g} \mathrm{MJ}^{-1}$, $1.786 \mathrm{~g} \mathrm{MJ}^{-1}$ and $1.291 \mathrm{~g} \mathrm{MJ}^{-1}$ respectively (Fig. 3). Samrat was noticed with the lowest radiation use efficiency value as well as the lowest amount of pod. PM05 had the highest value of RUE among the three varieties. The RUE of Meha was in between the RUE values of the other two varieties. Meha was also reported with a yield which was less than PM05 but greater than Samrat. Meha and PM05 used to intercept almost same amount of PAR per unit area in one day. But almost $20 \%$ less daily above ground biomass production was recorded from Meha. So, it was recognised with a RUE value less than PM05. The above findings can be supported by the work done by Tesfaye et al., (2006) where seed yield of major grain legumes were strongly and positively correlated with radiation use efficiency. 
RUE value irrespective of the varieties was also computed for the future yield prediction. The overall RUE value for green gram was noted as $1.4251 \mathrm{~g} \mathrm{MJ}^{-1}$ (Fig.4). Soltani et al. (2006) reported an average RUE of $1.0 \mathrm{~g} \mathrm{MJ}^{-1}$; Tesfaye et al. (2006) reported a range in RUE from 1.45 to $2.07 \mathrm{~g} \mathrm{MJ}^{-1}$ from several pulses. So, this estimated value was in conformity with results of the above mentioned studies. RUE based yield determining equation for green gram is as follows:

$\mathrm{Y}=1.4521 \Sigma$ IPAR -0.8615

where, $\mathrm{Y}=$ biomass $\left(\mathrm{g} \mathrm{m}^{-2} \mathrm{day}^{-1}\right), \mathrm{IPAR}=$ Accumulated IPAR in MJ $\mathrm{m}^{-2}$ day $^{-1}$.

Before applying the above equation for assessment of future yield, the predicted yield derived from this RUE based equation was compared with district level actual yield data of Nadia District (for the period of 2007 to 2016). The predicted yield data was plotted against observed yield and it was observed that the points are along 1:1 line (Fig. 5). This clearly shows that the predicted data matches well with observed one. Very low root mean square error (RMSE) value (0.05) and mean absolute error (MAE) value (0.04) indicates the model accuracy.

\section{Assessment of future yield of green gram from $R U E$}

Variation of physiological maturity, biomass production and yield of green gram under future climatic condition were observed in this study. There was clear indication of early maturity with increasing temperature from 2040 to 2090. The biomass and yield also showed a decreasing trend with passing years. RCP 8.5 being an extreme scenario projected more reduced crop duration, biomass and yield than RCP 4.5. Crop duration was 3 to 9 and 4 to 15 days less than present the condition under RCP 4.5 and 8.5 respectively (Table 5). Karande et al. (2018) also reported 8 to 15 days of advanced maturity in green gram for different crop management treatments in later part of this century. For 2040 under $\mathrm{RCP} 4.5$, the reduction in biomass and crop yield was marginal, only $1.62 \%$ and $4.38 \%$ respectively. The results indicated that the yield drop might become as high as $16.23 \%$ in 2090 . According to the prediction under RCP 8.5 scenario, biomass production in 2090 would be declined to $2.01 \mathrm{t}$ ha ${ }^{\mathrm{F}}$ which is only $83 \%$ of existing one. Yield of green gram was also estimated to decrease by 8 to $19.5 \%$ during 2040-2090 time period. About 7.5 to $21.3 \%$ declined grain yield for various treatments during 2071-2100 period was observed for Anand district of Gujarat through DSSAT4.6 (CROPGRO) model (Karande et al., 2018). The findings of our RUE based analysis are in tune with these model based analysis. It is also observed that the magnitude of yield reduction of green gram compared to other common crops in the study region is less. Yadav et al. (2012b) concluded that different varieties of wheat would be reduced by $38-43 \%$ during $2070-2100$. Wet-season rice and mustard of West Bengal would experience $20-27.8 \%$ and $20-33.9 \%$ yield decrease respectively in 2025-2050 period (Banerjee et al., 2014). Results obtained by Dubey et al., (2011) showed that with every $0.1^{\circ} \mathrm{C}$ increase in maximum and minimum temperature, the yield of the chickpea was declined considerably. Their results confirmed that for $1^{\circ} \mathrm{C}$ rise in maximum temperature the chickpea yield will decrease up to $29.88 \%$.

\section{CONCLUSIONS}

The study established the strong association between IPAR and production as well as the greater efficiency of RUE than other features to confirm the probable yield. It can be concluded from the field observations that $P M 05$ variety can have the highest radiation utilization potential and this variety has the capacity of providing highest yield compared to other two varieties. So, it can be suggested that PM05 is the most suitable variety for the lower Indo-Gangetic region. The observations of the study suggest that values of RUE are also helpful to develop radiation based models which can provide a general indication of green gram production. The similarity between the outcomes of the present study and the dynamic model based researches prove the efficiency of this very simple method which requires only radiation and temperature data. Moreover, several experiments performed by different researchers showed greater yield reduction in future in other commonly grown crops than green gram. This would be beneficial in terms of profitability as well as soil health. This kind of studies with further modification can carried out with the aim of alleviating the production levels, foretelling and determining production potential of crops.

Conflict of Interest Statement: The author(s) declare(s) that there is no conflict of interest.

Disclaimer: The contents, opinions, and views expressed in the research article published in the Journal of Agrometeorology are the views of the authors and do not necessarily reflect the views of the organizations they belong to.

Publisher's Note: The periodical remains neutral with regard to jurisdictional claims in published maps and institutional affiliations.

\section{REFERENCES}

Banerjee, S., Das, S., Mukherjee, A., Mukherjee, A., and Saikia, B. (2014). Adaption strategies to combat climate change effect on rice and mustard in Eastern India. Mitig. Adapt.Strateg. Glob. Change, doi: 10.1007/s11027014-9595-y.

Brar, G.S., Varshenya, M.C., Sabale, R.N., and Salunke, S.S. (2006). PAR distribution and light use efficiency in Capsicum (Capsicum frutescens L.) crop canopy. J. Agrometeorol., 8(2): 197-200.

Dubey, S.K., Uma, S. and Singh, S. K. (2011) Impact of climate change on pulse productivity and adaptation strategies as practiced by the pulse growers of Bundelkhand region of Uttar Pradesh. J.Food Legum., 24(3):230-234.

Gallo, K. P.and Daughtry, T. (1986). Techniques for measuring intercepted and absorbed Photosynthetically active radiation in corn canopies'. Agron. J., 78: 752-756.

Karande, B.I., Patel, H.R., Yadav, S.B., Vasani, M.J., and Patil, D.D. (2018). Impact of Projected Climate Change on Summer Mungbean in Gujarat, India. Int. J. Curr. Microbiol. App. Sci., 7(8): 4178-4189. 
Kiniry, J.R., McCauley, G., Xie, Y., and Arnold, J.G. (2001). Rice parameters describing crop performance of four cultivars. Agron. J.,53: 1354-1361.

Koocheki, A., Mahallati, MN., Solouki, H., and Karbor, S. (2016). Evaluation of Radiation Absorption and use Efficiency in Substitution Intercropping of Sesame (Sesamum Indicum L.) and Mung Bean (Vigna Radiata L.). Adv. Plants Agric. Res., 3(5): 00109.

Kumar, N., Tripathy, R. S., Jain, D. R.,Vishwakarma, A. K., Madhu, M., Rao, B. K., Tripathi, K. P. and Anurajan. (2012). Sensitivity of wheat crop to projected climate change in non-traditional areas. J. Agrometeorol., 14(1): 82-86.

Nobel, P.S. (1980). Interception of Photosynthetically Active Radiation by Cacti of Different Morphology. Oecologia, 45: $160-166$

Soltani, A., Robertson, M. J.,Rahemi-Karizaki, A., Poorreza, J., and
Zarei, H. (2006).Modelling biomass accumulation and partitioning in Chickpea (Cicer arietinum L.). J. Agron. Crop Sci., 192(5): 379-389.

Tesfaye, K., Walker, S., and Tsubo, M. (2006). Radiation interception and radiation use efficiency of three grain legumes under water deficit conditions in a semi-arid environment. Eur. J .Agron., 25: 60-70.

Yadav, S. B., Patel, H.R., Patel, G. G., Lunagaria, M. M., Karande, B. I., Shah, A. V., and Vandey, P. (2012a). Calibration and validation of PNUTGRO (DSSAT v4.5) model for yield and yield attributing characters of kharif groundnut cultivars in middle Gujarat region. J. Agrometeorol., 14: Special Issue, 24-29.

Yadav, S. B., Patel, H. R.; Kumar, A. and Pandey, V. (2012b). Impact assessment of climate change on wheat yield of middle Gujarat region. Int. J. Agri. Sci. \& Tech., 1 (1): 5-13. 